\title{
A PERSPECTIVA DE REDES NA INTERNACIONALIZAÇÃO DE EMPRESAS BRASILEIRAS DE CONSTRUÇÃO CIVIL: O CASO VALE E BNDES EM MOÇAMBIQUE
}

\section{RESUMO}

A proposta deste artigo é analisar, a partir da perspectiva de redes, o processo de internacionalização de empresas brasileiras e em como esse movimento é influenciado por entes governamentais. Em outros termos, objetiva-se pensar os negócios internacionais não como sendo uma atividade que afeta apenas uma empresa, mas que tenha um impacto sobre todas interações dentro de suas redes, as quais congregam a esfera pública. O referencial teórico que deu suporte para análise do caso foi um framework integrativo entre a perspectiva de redes e a teoria institucionalista. O método de pesquisa aplicado foi o estudo de caso, realizado a partir da triangulação na coleta e análise dos dados empíricos, visando uma maior visão a respeito da cadeia internacionalizada. A conclusão deste estudo foi que a internacionalização das grandes empreiteiras brasileiras para Moçambique e a consolidação delas nesse país tiveram e ainda têm grande influência do papel de suas redes.

Palavras-chave: Internacionalização de Empresas; Perspectiva de Redes; Teoria Institucional.

THE NETWORKS PERSPECTIVE ON THE BRAZILIAN HEAVY CONSTRUCTION FIRMS INTERNATIONALIZATION PROCESS: THE CASE OF VALE AND THE BNDES IN MOZAMBIQUE

\begin{abstract}
The purpose of this article is to analyze, from the networks perspective, the process of internationalization of Brazilian companies and how this movement is influenced by government entities. In other words, the objective is to think international business not as an activity that affects only one company, but as a movement that has an impact on all interactions within their networks, which includes the public sphere. The theoretical framework that supported the analysis of the case was an integrative framework that conjugates the perspective of networks and the Institutional Theory. The research method used was the case study, carried out from the triangulation of the information obtained by the collection and analysis of empirical data, in order to get a greater view of the internationalized chain. The conclusion of this study was that the internationalization of major Brazilian construction firms to Mozambique and their consolidation in that country had and still have great influence of their networks.
\end{abstract}

Keywords: Internationalization; Networks Perspective; Institutional Theory. 


\section{LA PERSPECTIVA DE LA RED EN LA INTERNACIONALIZACIÓN DE LAS EMPRESAS BRASILEÑAS CONSTRUCCIÓN: EL VALLE DE CASO Y BNDES EN MOZAMBIQUE}

\section{RESUMEN}

El propósito de este artículo es analizar, desde la perspectiva de la red, el proceso de internacionalización de las empresas brasileñas y cómo este movimiento se ve influida por las entidades gubernamentales. En otras palabras, el objetivo es pensar en los negocios internacionales no como una actividad que afecta a una sola empresa, pero tiene un impacto en todas las interacciones dentro de sus redes, que reúnen a la esfera pública. El marco teórico que tiene soporte para el examen del caso era un marco integrador desde la perspectiva de las redes y la teoría institucionalista. El método de investigación utilizado fue el estudio de caso, realizado a partir de la triangulación en la recolección y análisis de datos empíricos para la mayor visión de la cadena internacionalizada. La conclusión de este estudio fue que la internacionalización de las grandes empresas constructoras brasileñas a Mozambique y les consolidarse en ese país tuvo y todavía tiene gran influencia sobre el papel de sus redes.

Palabras clave: Internacionalización de las Empresas; Perspectiva de las Redes; Teoría Institucional.

Bernardo Frossard Silva Rêgo ${ }^{1}$

Luis Antonio Rocha $\mathrm{Dib}^{2}$

Bernardo Bemvindo ${ }^{3}$

\footnotetext{
${ }^{1}$ Doutorando do Instituto de Pós-Graduação e Pesquisa em Administração da Universidade Federal do Rio de Janeiro COPPEAD/UFRJ. Brasil. E-mail: bernardofrossard@ hotmail.com

${ }^{2}$ Doutor em Administração pelo Instituto de Pós-Graduação e Pesquisa em Administração da Universidade Federal do Rio de Janeiro - COPPEAD/UFRJ. Professor do Instituto de Pós-Graduação e Pesquisa em Administração da Universidade Federal do Rio de Janeiro - COPPEAD/UFRJ. Brasil. E-mail: dib@coppead.ufrj.br

${ }^{3}$ Mestre em administração pelo Instituto de Pós-Graduação e Pesquisa em Administração da Universidade Federal do Rio de Janeiro - COPPEAD/UFRJ. Brasil. E-mail: bernardobemvindo@gmail.com
} 


\section{INTRODUÇÃO}

A internacionalização de empresas tem sido um assunto a continuamente despertar o interesse de pesquisadores. $\mathrm{O}$ aumento da importância do comércio internacional na economia mundial e os movimentos de globalização vividos nas últimas décadas aumentaram ainda mais o interesse no tema. Dunning \& Mucchielli (2001) já apontavam que embora o fenômeno da globalização não fosse recente, havia se acelerado nos últimos anos, com a adoção de estratégias verdadeiramente globais por muitas empresas. Os autores ressaltavam a criação de áreas de comércio comum, como a União Europeia, o Mercosul, a ASEAN e a NAFTA e os movimentos de integração regional como fatores que influenciaram mudanças estratégicas nas empresas.

No Brasil, a internacionalização das empresas nacionais também tem sido um tema recorrente nas pesquisas da área de administração. As mudanças ocorridas na economia brasileira na década de 1990 possibilitaram a inserção do país em um contexto global. A internacionalização passou a ser vista como um meio para aumentar a competitividade, através de ganhos de escala, além de assegurar e expandir mercados para as empresas (Alem \& Cavalcanti, 2005).

Apesar disso, as empresas brasileiras não têm um histórico de busca ativa por mercados internacionais, como destacaram Rocha, Silva \& Carneiro (2007): a internacionalização dessas firmas é tardia em comparação a outros países, mesmo na América Latina. Os autores acrescentam que, até os anos 1990, havia um baixo grau de envolvimento de firmas nacionais com exportação, e o investimento direto dessas empresas no exterior também era raro. Uma das explicações possíveis para esse fato, de acordo com os autores, é a existência de um mercado doméstico suficientemente grande e protegido em relação às importações. Esse cenário começou a se modificar após a abertura do mercado nos anos 90, que expôs a indústria nacional à concorrência estrangeira.

No atual ambiente macroeconômico do Brasil, porém, observa-se o crescimento de empresas nacionais e aumento da sua internacionalização, como nota-se nos números do levantamento feito pela Fundação Dom Cabral, no qual a internacionalização de empresas nacionais, em uma amostra de 62 multinacionais, cresceu $7 \%$ em 2014, passando de $22,9 \%$ em 2013 para 24,5\% (O Globo, 2015). No entanto, a base histórica desse processo no caso de firmas nacionais é recente, permitindo um conhecimento ainda restrito de experiências que levem em conta especificidades de empresas criadas no ambiente econômico e cultural do país (Rocha et al., 2007).

Nesse cenário, o Banco Nacional de Desenvolvimento Econômico e Social (BNDES) passou, a partir de 1994, a apoiar a internacionalização de empresas brasileiras. De acordo com Flynn (2007), nos últimos 15 anos, o banco foi responsável por US\$ 30 bilhões para apoiar as exportações. Essa tendência de crescimento teve seu pico no final do governo Lula, com desembolsos nas linhas de apoio ao comércio exterior atingindo US\$ 11,3 bilhões em 2010 e, em 2014, esse valor foi de US\$ 4 bilhões (Machado, 2015) - essa queda corresponde à redução do comércio global, principalmente de commodities aliada à crise econômica interna. Desse modo, nota-se que o BNDES teve um papel crescente para o aumento da presença de empresas brasileiras no exterior.

Assim, o objetivo dessa pesquisa foi investigar, como as empreiteiras brasileiras se internacionalizaram para Moçambique. Para isso buscou-se, em primeiro lugar, verificar se a política de créditos disponibilizada pelo BNDES auxilia na formação de redes de empresas. Também procurou-se descobrir se componentes de uma rede seguiriam o caminho de internacionalização de um participante da mesma. Para isso, foi utilizado um estudo de caso único, da empresa Vale atuando em Moçambique, cujas informações foram obtidas através de entrevistas e dados secundários para que seja possível fazer uma triangulação.

$\mathrm{O}$ estudo deu destaque a Teoria Institucional (North, 1990) para embasar o papel das instituições na internacionalização, bem como à perspectiva de redes (Johanson \& Mattson, 1993) cujo o intuito foi o de mostrar como interações dentro de uma rede levam à empresa ao exterior. Como resultado, mostrou-se que grandes construtoras brasileiras - Camargo Corrêa, OAS, Odebrecht - iniciaram suas operações em Moçambique em função da atuação da Vale e do financiamento do BNDES que possui como contrapartida a contratação de serviços/exportação de produtos nacionais, sendo o processo de internacionalização para esse país uma consequência tanto da rede de contatos, quanto da instituição "apoio governamental".

O artigo, então, estrutura-se da seguinte forma: após essa breve introdução, é apresentada a perspectiva de redes utilizada para embasar a análise, bem como a Teoria Institucional, e, na sequência, a metodologia utilizada. Em seguida, são descritos breves históricos da Vale e do BNDES para, na seção seguinte, ser analisado o caso da atuação daquela empresa em Moçambique. Por fim, é feita a conclusão e são oferecidas sugestões de pesquisas a partir das descobertas apresentadas.

\section{REFERENCIAL TEÓRICO}

De acordo com Forsgren (2002), o trabalho de Carlson (1966) construiu as bases para o que passou a ser conhecido como o Processo de Internacionalização do Modelo de Uppsala (Johanson \& WiedersheimPaul, 1975; Johanson \& Vahlne, 1977). Esse modelo tem como hipótese básica o fato de que a falta de 
conhecimento sobre determinado mercado internacional é o maior obstáculo para a empresa operar no exterior, mas que, apesar disso, tal conhecimento pode ser adquirido (Johanson \& Vahlne, 1977; Forsgren, 2002; Johanson \& Vahlne, 2009). Outro pilar de sustentação do modelo é que as decisões acerca dos investimentos são feitas de forma gradual devido, principalmente, às incertezas, o que faz com que as organizações iniciem via exportação e, em seguida, desenvolvam métodos de maior controle (Johanson \& Vahlne, 1977). Dessa forma, o Modelo de Uppsala lida com a forma como as organizações aprendem e o impacto desse aprendizado no comportamento organizacional (Forsgren, 2002).

Johanson \& Vahlne (1977) afirmam que o desenvolvimento do conhecimento ocorre quando as empresas operam em determinado mercado e esse, por sua vez, eleva o nível de comprometimento da organização, já que o conhecimento pode somente ser adquirido através da experiência direta (Björkman \& Forsgren, 2000). Isso ocorre porque somente fazendo negócios em determinado país pode-se aprender sobre o comportamento dos consumidores, intermediários, competidores e autoridades públicas e esse tipo de conhecimento nunca poderá ser substituído por informações gerais e questionários (Johanson \& Vahlne, 2009). Segundo Hemais \& Hilal (2003), esse conhecimento e esse comprometimento são consequências do crescimento da empresa; desse modo, quando o mercado interno fica saturado e a ampliação da firma torna-se mais difícil, ela passa a buscar lugares para se expandir.
De modo a explicar a busca por locais de expansão, Johanson \& Vahlne (1977) apropriaram-se do termo distância psíquica. Segundo diversos autores (Silva; Rocha \& Figueiredo, 2007; Hákanson \& Ambos, 2010; Ferreira, 2011), essa expressão foi cunhada por Beckerman (1956) ao observar que o comércio bilateral europeu não era influenciado somente pela distância física, mas que outros fatores também eram observados. Johanson \& Vahlne (1977) a definem como sendo a soma dos fatores que impedem ou perturbam o fluxo de informações que chegam e que são enviadas para o mercado externo. Os autores citam ainda que os fatores que criam a distância psíquica remetem às diferenças de linguagem, educação, práticas de negócios, cultura e desenvolvimento industrial. Para Czinkota \& Ursic (1991), contudo, a distância psíquica está perdendo relevância na medida em que a comunicação, a infraestrutura e os transportes estão se desenvolvendo, tornando os mercados homogêneos.

Uma das características das empresas em face dessas mudanças é a transição da eficiência individual para a coletiva, na qual a competitividade é relacionada ao desempenho de redes interorganizacionais e não mais de empresas isoladas (Garcia; Lima \& Carvalho, 2010). Dada essa transição, foram feitas revisões aos construtos explorados pelo Modelo de Uppsala, dando destaque às redes (Johanson \& Mattson, 1993; Johanson \& Vahlne, 2009; Vahlne, Ivarsson \& Johanson, 2011; Vahlne \& Johanson, 2013), cuja última revisão resume-se na figura abaixo:

Figura 1 - O Modelo de Uppsala Revisitado 2013

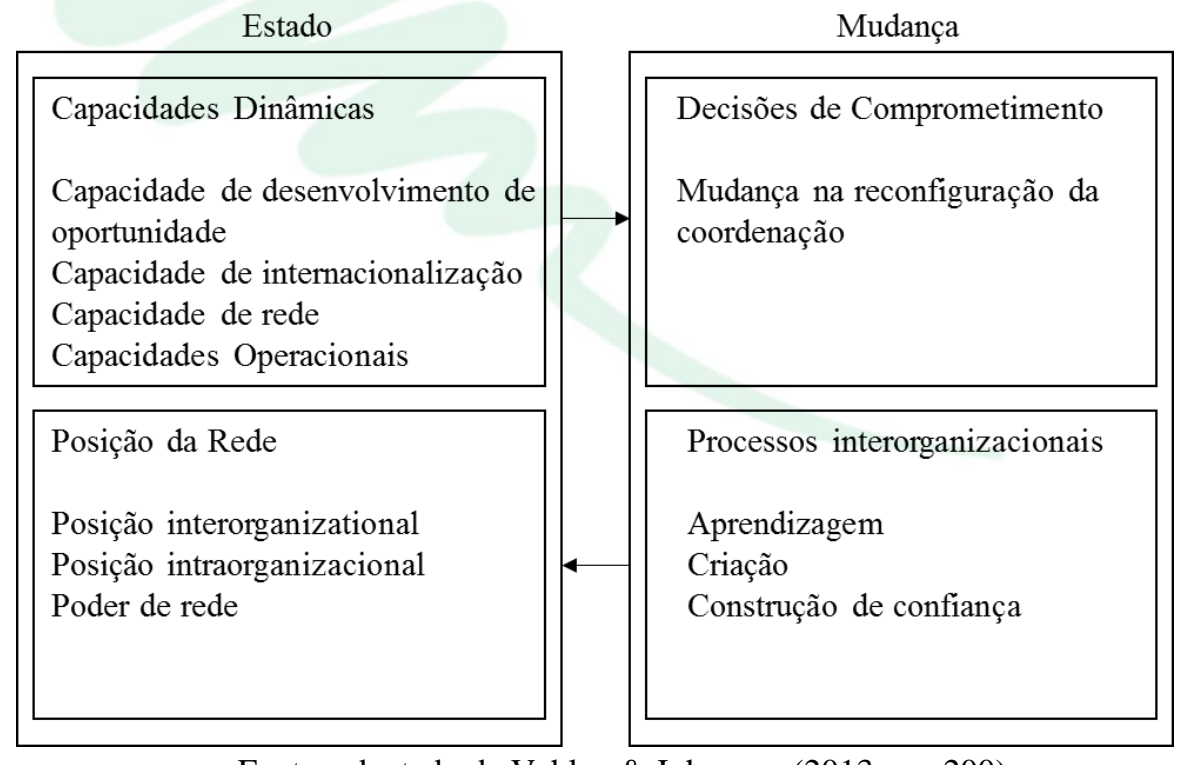

Fonte: adaptado de Vahlne \& Johanson (2013, pp. 200) 
Essa nova configuração, mostra um processo composto por dois tipos de variáveis de mudança: as decisões que comprometem a organização com certos parceiros, projetos ou estratégias e processos interorganizacionais em curso de aprendizagem, criação e construção de confiança. Além disso, Vahlne \& Johanson (2013) destacam que o modelo é dinâmico no sentido de que, quando um novo conhecimento é aprendido ou criado, ele tem um impacto sobre o aprendizado contínuo, bem como sobre as decisões de comprometimento. Do mesmo modo, essas decisões terão um impacto sobre o desenvolvimento do conhecimento posterior.

Apesar de ter passado a figurar no Modelo de Uppsala a partir dos anos 2000, a Perspectiva de Redes teve seu início com o Paradigma da Interação, sendo resultado de trabalhos do Industrial Marketing and Purchasing Group (Anderson; Hákanson \& Johanson, 1994). Esse grupo formou-se durante a década de 1970 por estudiosos de diversas universidades, sendo que alguns deles eram de Uppsala. Eles focavam suas pesquisas em relacionamentos entre empresas e, pesquisando sistemas de distribuição, internacionalização de indústrias e estratégias de marketing, chegaram à conclusão de que outro fator apresentava relação com os relacionamentos observados entre os atores do mercado, tendendo a ser de longo prazo, estável e dinâmico (Johanson \& Mattson, 1993; Coviello, 2006). Assim, Björkman \& Forsgren (2000) afirmam que a Perspectiva de Redes, ao invés de explicar a internacionalização da firma via fatores econômicos, utiliza-se de laços cognitivos e sociais que ocorrem entre os atores que se relacionam.

A utilização de laços sociais fez com que Anderson et al. (1994) definissem uma rede como um conjunto de relacionamentos de negócios interconectados, nos quais as relações de troca ocorrem entre as empresas, que são conceituadas como atores coletivos. Assim, Coviello \& Munro (1997) descreveram os mercados como sendo sistemas de relações sociais e industriais entre, por exemplo, clientes, fornecedores, concorrentes, entes governamentais, familiares e amigos.

A empresa, utilizando os laços sociais, pode criar o novo conhecimento através de trocas na sua rede de relacionamentos, sendo a criação um resultado do confronto entre os conhecimentos do produtor e do usuário (Johanson \& Vahlne, 2009). Ainda segundo os autores, esse processo de criação de conhecimento não se separa das outras atividades relacionais, mas se encontra dentro delas. Isso acontece porque o conhecimento não é criado apenas pelas próprias atividades da empresa, mas também das atividades dos parceiros; e, como esses parceiros possuem outros relacionamentos, a base de conhecimentos das empresas expande-se. Ford \& Mouzas (2013) explicam que os relacionamentos ativam recursos e atividades, ou seja, todos os atores envolvidos dependem dos recursos e das atividades dos outros, as quais eles não controlam e, por sua vez, esses recursos e atividades são modificados nesses relacionamentos. Assim, a utilidade e o valor dos recursos de cada ator são determinados pelas maneiras pelas quais eles são ou podem ser combinados e desenvolvidos através das relações com os outros (Ford \& Mouzas, 2013).

Outro ponto importante é que essa perspectiva tem o processo de internacionalização como uma resultante do conhecimento experiencial e do comprometimento, mesmo que nenhum deles, agora, se refira aos países, mas sim aos relacionamentos existentes e potenciais (Johanson \& Valhne, 2009). De grande interesse é o conhecimento experiencial (Penrose, 1995), já que, desse modo, as empresas inicialmente acumulam conhecimento e desenvolvem relacionamentos no mercado doméstico (Sharma \& Blomstermo, 2003). Como consequência, as decisões são feitas conforme aparecem os problemas ou oportunidades, como, por exemplo, quando em face de uma decisão no mercado internacional, as empresas utilizam-se de soluções as quais já obtiveram sucesso no passado (Sharma \& Blomstermo, 2003). Essas oportunidades, para Johanson \& Vahlne (2009), são partes do conhecimento e, adicionando essa variável, eles consideram-nas o elemento mais importante no corpo de conhecimento da empresa, o que leva ao processo de internacionalização.

Soma-se ainda que, de acordo com a perspectiva de redes, com o intuito de ampliar o seu mercado, as empresas conseguem acessos privilegiados a informações, sendo essas provenientes da sua rede de relacionamentos; além disso, as oportunidades, muitas vezes, são resultados das atividades das empresas, o que agrega à sua base de conhecimentos (Johanson \& Vahlne, 2009). Dessa maneira, como algumas formas de conhecimento não estão disponíveis para todo o mercado, já que se encontram restritas aos membros de uma rede, o comprometimento com parceiros resulta na criação de conhecimento, o que implica na criação/descoberta de oportunidades.

Ser membro de uma rede, para Johanson \& Mattson (1993), perpassa pela hipótese básica do modelo de redes, na qual a empresa é dependente dos recursos controlados por outras, os quais ela consegue acesso devido à sua posição na rede. Assim, como o desenvolvimento do posicionamento demanda esforço e tempo e como a posição define as oportunidades apresentadas, o lugar ocupado na rede é visto como um ativo parcialmente controlado e intangível (Johanson \& Mattson, 1993). Ainda segundo os autores, por causa da interdependência entre as empresas, o uso de ativos em uma organização é dependente do uso dos ativos de outras. Como consequência, Ghauri, Lutz \& Tesfom (2003) salientam que a decisão das organizações de entrar em um relacionamento com outras é influenciada pelo desejo da administração de abdicar de autonomia, com o intuito de adquirir recursos de outros. Desse modo, é necessário que se construa uma base de 
conhecimento e de confiança mútuos (Barnir \& Smith, 2002).

Em termos de internacionalização, Johanson \& Mattson (1993) sugerem que o sucesso da organização em entrar em mercados internacionais é mais dependente dos seus relacionamentos nos mercados, tanto interno como externo, do que do país escolhido e suas características culturais. Assim, desse ângulo, a seleção do mercado externo e o modo de entrada partem mais das oportunidades criadas pelos contatos da rede do que somente pelas decisões estratégicas da empresa (Coviello \& Munro, 1995). Como consequência, Zain \& Ng (2006) afirmam que as redes servem para:

- Motivar a intenção inicial de internacionalização de uma empresa;

- Permitir às empresas superar as limitações de recursos humanos e financeiros;

- Fornecer informações sobre o que acontece no mercado;

- Dar acesso a relacionamentos adicionais e a canais estabelecidos;

- Dar acesso ao conhecimento do mercado local;

- Ajudar as empresas a obterem credibilidade inicial.

Por sua vez, os laços que compõem essas redes podem ser categorizados em formais, informais e intermediários. $\mathrm{O}$ primeiro responde pelo que é relacionado aos parceiros de negócios, ao passo que o segundo corresponde a amigos e familiares (Coviello \& Munro, 1995, 1997). Os intermediários, por fim, são referidos por McDougall \& Oviatt (2005, p. 545) como brokers, podendo ser uma organização de promoção à exportação ou um organizador de feiras, ou seja, são facilitadores da conexão entre o comprador e o fornecedor.

De acordo com Johanson \& Vahlne (2009), deve-se esperar que a expansão internacional seja um resultado, primeiramente, do desenvolvimento dos relacionamentos existentes. Em segundo, que seja proveniente do estabelecimento de relações com o consumidor - ou fornecedor - que são semelhantes àqueles aos quais já possuem relacionamentos. $\mathrm{E}$, por fim, a internacionalização da organização seria uma consequência do desenvolvimento de relações com empresas conectadas àquelas que eles já possuem um relacionamento. Assim, pode-se afirmar que tanto o aprendizado, como o desenvolvimento de redes, influenciam e são influenciados pelo processo de internacionalização (Welch \& Welch, 1996).

De um modo geral, Coviello \& Munro (1997) asseguram que a perspectiva de redes vai além do modelo incremental de internacionalização, ao concluírem que a estratégia da empresa emerge como um comportamento padrão influenciado por uma variedade de relacionamentos de sua rede. Nesse âmbito, os autores ainda afirmam que as oportunidades e ameaças apresentadas pela rede de relacionamentos podem inibir, facilitar ou direcionar o desenvolvimento internacional de uma empresa, podendo ainda influenciar o método de entrada. Já Coviello (2006) acredita que as redes irão abrir portas para as organizações ao prover acesso ao mercado, financiamentos, canais de distribuição, referências e um conjunto de contatos para o desenvolvimento interno e externo, culminando no fato de que, no mundo das redes, não existem barreiras específicas por países, já que as empresas se organizam para desenvolver e coordenar os relacionamentos (Johanson \& Vahlne, 2009).

Ainda segundo esses autores, a internacionalização de uma firma pode ser resultado das iniciativas de um intermediário, consumidor ou fornecedor, que esteja interessado em desenvolver um relacionamento com a empresa local. Os autores também destacam que os entrantes no mercado podem ser demandados a seguir um parceiro, acompanhando-o no processo de internacionalização. Além disso, Welch \& Welch (1996) afirmam que fatores contextuais e situacionais, como políticas governamentais, possuem um grande impacto no momento e nas características de decisões de expansão.

Essa diversidade em termos de agentes de uma rede motivou Oparaocha (2015) a subdividi-los em três grandes grupos: sociais, de negócios e institucionais, conforme a figura abaixo. 
Figura 2 - Tipologia de Redes

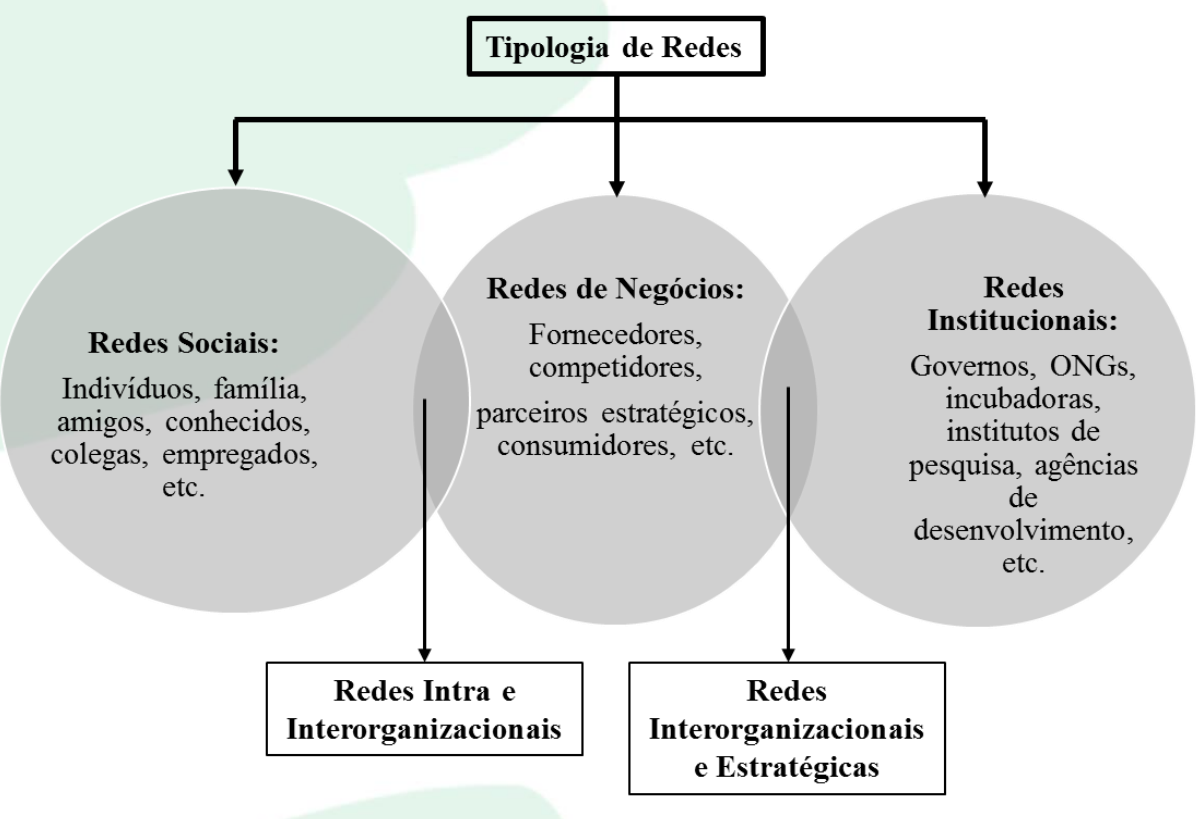

Fonte: Oparaocha (2015, pp. 864)

De acordo com Oparaocha (2015), as redes institucionais representam as relações que podem existir entre uma firma e as que o autor chama de "instituições de livre acesso". Em seu entendimento, um dos objetivos das redes institucionais é o de proporcionar apoio e criar uma atmosfera que possa fomentar o investimento externo e fomentar o negócio, tanto local quanto internacionalmente. Além disso, seus benefícios refletem-se no crescimento geral das empresas, no setor industrial/comercial e na economia regional ou nacional (Audet \& St-Jean, 2007).

Já as relações de interorganizacionais, por sua vez, são colaborações técnicas e processuais, em sua maioria, que visam a expansão dos negócios e o aumento da rentabilidade (Huggins, Johnston, \& Thompson, 2012). Deve notar-se que a interseção entre as redes institucionais e de negócios não incorporam as mesmas características, sugerindo que existe uma distinção clara entre elas (Slotte-Kock \& Coviello, 2009). Nesse caso, as redes institucionais focam na interação de uma firma com órgãos públicos e semipúblicos para obter vantagens dos recursos que não podem ser obtidos através de intercâmbios sociais (Audet \& St-Jean, 2007).

Essa discussão sobre redes institucionais remete a Teoria Institucional, a qual segundo North (1990, p. 3) coloca as instituições como sendo "as regras do jogo em uma sociedade", ou seja as transições institucionais são definidas como uma série de mudanças fundamentais introduzidas nas regras do jogo, sendo essas formais ou informais, que afetam as organizações, que seriam jogadores. Peng (2006) e Scott (2008) ainda acrescentam que, apesar de possuírem várias funções, o principal papel das instituições é o de reduzir as incertezas e prover significado. Nesse sentido, elas fazem-no para diferentes atores, condicionando as regras e as normas que regulam o comportamento e definindo os limites para o que é legítimo. Esses atores, por outro lado, são guiados pelos seus interesses e fazem suas escolhas dentro de um arcabouço institucional dado ao ambiente (Lee, Peng \& Barney, 2007).

É em meio a esse cenário que Arrow (1998) afirma que as instituições se desenvolvem em resposta as falhas de marcado. Mudambi \& Navarra (2002) adicionam que o papel das instituições é estritamente relacionado a sua habilidade de resolver as falhas de mercado, podendo ser consideradas como ferramentas que possibilitam o funcionamento eficaz das estruturas econômicas do mercado. Assim, o papel que as instituições podem desempenhar na sociedade é geralmente visto como necessário para cumprir duas tarefas principais: a redução dos custos de transação e os custos de processamento de informações necessárias para a tomada de decisões (Mudambi \& Navarra, 2002). Ademais, North (1990) também entende que as instituições devem reduzir os níveis de incerteza e de instabilidade nas sociedades.

Para Mudambi \& Navarra (2002) a importância das instituições na literatura de negócios internacionais deriva do fato de que elas representam os principais fatores imóveis em um mercado globalizado. Em um ambiente internacional caracterizado pela mobilidade de firmas e de fatores de produção, os sistemas jurídicos, políticos e administrativos tendem a ser o quadro internacionalmente imóvel cujos custos determinam a atratividade de uma localização. As instituições afetam, desse modo, a capacidade das firmas de interagir e, portanto, de afetar os custos de 
transação e de coordenação relativos à produção e à inovação.

Pode-se concluir então que os mercados que são semelhantes em estrutura política, estrutura de mercado ou cultura representam menor incerteza, logo os custos de entrada são relativamente mais baixos. Os investidores estariam, portanto, mais propensos a entrar em países onde o regime de política é relativamente fácil de prever (Vernon, 1971 apud Mudambi \& Navarra, 2002). Da mesma forma, os investidores são menos propensos a entrar em países que são culturalmente distantes e têm estruturas diferentes de organização (Hanson II, 1999).

É nesse momento que, segundo Bell (2002) entra o conceito de rede política. Ela pode ser definida como um "padrão estruturado de interação entre os atores-chave em uma dada arena política pública, seja ela política de saúde, política econômica ou outras quaisquer" (Bell, 2002, p. 8). Ainda segundo o autor, os principais intervenientes nessa esfera, normalmente, são atores estatais (políticos, burocratas) e atores nãoestatais (empresários, sindicalistas) que negociam e exercem o poder e detém os recursos políticos. Como tal, uma rede política não é uma instituição, mas um conjunto de comportamentos entre os atores que é fortemente influenciado por fatores institucionais.

A partir daí, pode-se afirmar que cada organização é formada por seu próprio ambiente institucional interno, que consiste nas estruturas, sistemas e práticas estabelecidas anteriormente (Meyer \& Rowan, 1977), e pelo ambiente institucional externo, o qual partilha com muitas outras organizações (Granovetter, 1985). Teóricos institucionais também argumentam que o que move as atividades organizacionais é o desejo da organização de adequarse ao seu ambiente institucional externo, enquadrandose às pressões institucionais de outras organizações (Martinez \& Dacin, 1999).
Globerman \& Shapiro (1999), seguindo esse pensamento, afirmam que as diferenças institucionais são significativas para as multinacionais que operam em diferentes contextos institucionais. No caso de países emergentes, arranjos institucionais fracos podem aumentar as assimetrias de informação, assim as empresas enfrentam maiores riscos relacionados (Meyer, 2001), precisando dispor-se de mais recursos em busca de informações (Tong, Reuer \& Peng, 2008). De acordo com Peng \& Heath (1996), nesses locais onde as instituições legais são fracas, as firmas devem contar mais com estratégias baseadas em relacionamento, sendo esses com outras firmas, com agentes de distribuição ou com autoridades do governo.

Relativo ao que foi dito, Peng \& Parente (2012) dizem que comparadas à multinacionais de países desenvolvidos, as de países emergentes possuem um relacionamento diferenciado com os seus governos e que, adicionalmente, possuem vantagens específicas de país e de firma, como recursos naturais, economia de escala, mão de obra e custo de capital. Nesse contexto, os autores ainda afirmam que as multinacionais dos países emergentes estão acostumadas a operar em um ambiente em que a estrutura financeira não é apropriada e em que há falta de mecanismos para proteger os investidores, somando ainda o baixo nível de transparência dos sistemas regulatórios e do ambiente de negócios. Assim, em relação aos países emergentes, os governos vêm assumindo um papel importante na promoção e na proteção da atividade econômica (Frischtak, 2003), já que para North (1990), as instituições econômicas estabelecem os incentivos voltados para as entidades domésticas e estrangeiras. Portanto, a visão institucional investiga como as regras e regulamentos dos governos influenciam nos negócios e, em consequência, nas estratégias das empresas (Meyer \& Peng, 2016).

Tabela 1 - Quadro-Resumo das Teorias x Elementos Considerados

\begin{tabular}{|c|c|l|}
\hline TEORIA & AUTORES & \multicolumn{1}{|c|}{ ELEMENTOS CONSIDERADOS } \\
\hline Modelo de Uppsala & $\begin{array}{c}\text { Johanson \& Vahlne (1977, } \\
2009)\end{array}$ & $\begin{array}{l}\text { Falta de conhecimento como obstáculo para operar no } \\
\text { exterior. }\end{array}$ \\
\hline Perspectiva de Redes & Johanson \& Mattson (1993) & $\begin{array}{l}\text { Sucesso na internacionalização é mais dependente dos } \\
\text { relacionamentos do que do país. }\end{array}$ \\
\hline Perspectiva de Redes & Johanson \& Vahlne (2009) & $\begin{array}{l}\text { Expansão internacional é resultado de relacionamentos } \\
\text { anteriores. }\end{array}$ \\
\hline Perspectiva de Redes & Ford \& Mouzas (2013) & Relacionamentos ativam recursos e atividades. \\
\hline Perspectiva de Redes & Oparaocha (2015) & Redes interorganizacionais e estratégicas (institucionais) \\
\hline Teoria Institucional & Peng \& Heath (1996) & $\begin{array}{l}\text { Em países emergentes, as firmas devem contar mais com } \\
\text { relacionamentos. }\end{array}$ \\
\hline Teoria Institucional & $\begin{array}{c}\text { Frischtak (2003); Peng \& } \\
\text { Parente (2012) }\end{array}$ & $\begin{array}{l}\text { Em países emergentes, o governo tem um papel preponderante } \\
\text { na internacionalização de suas empresas. }\end{array}$ \\
\hline Teoria Institucional & Peng (2006); Scott (2008) & Instituições reduzem incertezas. \\
\hline
\end{tabular}

Fonte: elaborado pelos autores 


\section{METODOLOGIA}

A definição da pergunta é fundamental para o sucesso de uma pesquisa. Segundo Yin (1994) a forma como ela é elaborada fornece um melhor caminho para a execução da pesquisa, já que alguns tipos de métodos se adequam melhor a determinados tipos de pergunta. A pergunta deve apresentar ainda a substância da pesquisa, ou seja, sobre o que ele trata. O objetivo da pesquisa deste trabalho foi, a partir do caso de uma das maiores e mais internacionalizadas empresas brasileiras, analisar como o seu processo de internacionalização para Moçambique possibilitou que membros de sua rede, no caso as empreiteiras, tivessem sua primeira experiência nesse mercado. Assim a pergunta principal do estudo foi: "Como as empreiteiras brasileiras se internacionalizaram para Moçambique?". As principais teorias contempladas para a análise desse caso e para responder à pergunta foram: o Modelo de Uppsala, a perspectiva de redes e a Teoria Institucional, conforme discutidos anteriormente.

Visando uma resposta à pergunta supracitada, o presente artigo emprega um método qualitativo, exploratório e descritivo, sendo baseada no método do estudo de caso, propiciando uma visão aprofundada, integrada e contextualizada do processo em questão. Apesar de o método inviabilizar a generalização estatística dos resultados, ele possibilita ao pesquisador investigar a realidade explorada. Além disso, como é salientado por Yin (1994), esse é um método no qual não há controle sobre os eventos, sendo, desse modo, adequado para estudo de fenômenos contemporâneos. O estudo de caso utiliza, para isso, a observação direta dos acontecimentos e entrevista com pessoas envolvidas, além de análises históricas (Yin, 1994).

De acordo com Zanni, De Moraes \& Mariotto (2011), estudos de casos únicos permitem gerar insights mais valiosos, já que o foco em um caso permite uma visão particular, mais profunda, levando a compreensão mais valiosa dos fenômenos e circunstâncias do que ocorre na comparação de dois casos ou mais. Os estudos de casos únicos também servem para preencher a lacuna de especificidade deixada pelos estudos que buscam generalização empírica.

A escolha da empresa foi realizada levando em conta seu tamanho e a sua importância para economia do país, além de se beneficiar das políticas nacionais. A Vale é a maior exportadora do Brasil, por exemplo, em 2012, segundo dados da revista Exame (2013), a empresa manteve seu posto como maior exportadora do país, com um total exportado chegando a 25,5 bilhões de dólares, sua participação no total das exportações nacionais foi de $10,5 \%$.

Ademais, a Vale está entre as empresas brasileiras mais internacionalizadas segundo a Fundação Dom Cabral (2014). Além disso, considerando a balança comercial brasileira, o impacto de suas exportações é multiplicado em função da cadeia que a cerca, levando o investimento no exterior a "transbordar para trás", movimentando outras firmas prestadoras de serviço. Portanto, entende-se como sendo uma firma interessante para ser investigada das qual as lições apreendidas são informativas em relação à média das organizações (Yin, 1994). Diante disso, análises aprofundadas são adequadas podendo servir como fonte de pesquisa para estudos científicos futuros.

Quanto ao processo de coleta dos dados, o que norteou este trabalho foi a triangulação, explicada por Yin (1994) como sendo uma forma de explicar um fato mediante a convergência de diversas fontes, dando maior credibilidade ao estudo. Assim, foram utilizados dados primários e secundários provenientes do levantamento bibliográfico em jornais e revistas, bem como documentos institucionais da empresa relatórios anuais e sites institucionais -, além de entrevistas semiestruturadas realizadas com representantes da Vale - um diretor internacional e um de iniciativas estratégicas - e de firmas encontradas em sua rede - gerentes internacionais da Camargo Corrêa e da OAS e um engenheiro da Odebrecht. A triangulação nesse tipo de pesquisa é de grande importância, já que permite minimizar possíveis vieses do entrevistado ou de erros de interpretação do entrevistador. Nesse âmbito, é válido aqui destacar a presença de vieses tanto na observação do pesquisador, quanto nas falas dos entrevistados.

Em termos de limitação do estudo, este focou-se somente no que tange às redes de negócios das empresas, sem levar em consideração a perspectiva técnica, ou seja, partiu-se do pressuposto que as firmas estudadas apresentam competências técnicas suficientes para a competição e para a atuação em outros países. Além disso, conforme explicitado, o trabalho limita-se ao estudo de uma parte da rede (construtoras-Vale-BNDES) internacionalizando-se para um país (Moçambique) para a realização de um projeto (mina de Moatize). Assim, a partir daí, pode-se apresentar novos estudos no que tange a outros membros da rede, outros países/projetos, bem como novas interações entre esses mesmos membros.

\section{APRESENTAÇÃO DOS CASOS}

Vale

Seguindo a onda de nacionalismo e de estatização da economia, em junho 1942, o então presidente Getúlio Vargas assina o Decreto-Lei no 4.352 que criava a Companhia Vale do Rio Doce (CVRD). Os bens, incluindo estoques de minério, instalações, veículos e utensílios, da Companhia Brasileira de Mineração e Siderurgia S.A. e da Companhia Itabira de Mineração foram incorporados ao patrimônio da União (Vale, 2012). 
A maior preocupação da CVRD nos primeiros anos era atingir sua meta de exportação de minério de ferro. Para isso a empresa investiu pesado em infraestrutura e na compra de equipamentos, necessitando logo em seus primeiros anos de um aumento de capital e de um novo empréstimo junto ao Eximbank. Com o processo de reconstrução da Europa no pós-guerra a demanda mundial de minério voltou a crescer e a CVRD aumentou paulatinamente suas exportações nos últimos anos da década de 1940 e na década de 1950 (Vale, 2012).

Com a chegada do governo militar ao país a CVRD foi aberta ao capital estrangeiro, em 1964 o Banco Interamericano de Desenvolvimento (BID) aprovou o empréstimo de US\$28,8 milhões usado para vários investimentos na área de transporte, sobretudo a expansão do Terminal Marítimo de Tubarão. Os investimentos possibilitaram uma grande expansão da presença da CVRD no mercado externo entre os anos de 1968 e 1978. (Vale, 2012).

Na década de 1990, foi criado o Programa Nacional de Desestatização (PND) com o intuito de equilibrar a balança comercial e as contas públicas, de forma a prolongar a estabilidade gerada pelo Plano Real. Assim, o vencedor do leilão referente à venda da Vale foi um consórcio formado por investidores nacionais e estrangeiros, que arrematou $41,73 \%$ das ações pertencentes ao governo brasileiro, cujo financiamento foi garantido pelo BNDES.

$\mathrm{O}$ foco internacional que a empresa ganharia na década seguinte, é simbolizado pelo início da comercialização das ações da companhia na Bolsa de Valores de Nova York (NYSE), no ano 2000. Em 2001 a empresa, buscando parcerias com seus vizinhos sulamericanos para explorar commodities cuja exploração no Brasil era pequena, a firmou uma joint-venture com a chilena Codelco, a maior produtora de cobre do mundo. Em 2004, a CVRD chegou à China, com um investimento de 10,6 milhões de dólares, ela participou, junto com sócios japoneses, da criação da Shandong Yankuang International Coking Company. A China se transformaria nos anos 2000 no maior mercado de commodities do mundo, devido suas altas taxas de crescimento e sua necessidade de investimentos para renovar sua infraestrutura. Porém a aquisição internacional mais notável do período foi sem dúvida a da canadense Inco. Na época a Inco detinha as maiores reservas mundiais de níquel e era a segunda maior produtora global dessa commodity.

Em 2007 foi a vez da CVRD se internacionalizar para a Austrália, onde adquiriu a AMCI, mineradora que operava vários ativos de carvão, por US\$ 656 milhões. Já em 2008 a Vale fechou parceria com o governo de Omã. Uma planta de pelotização de minério foi estabelecida no país para atender melhor as características dos fornos predominantes nas siderúrgicas da região do Oriente Médio. No mesmo ano houve a chegada a Moçambique onde a Vale venceu uma licitação para explorar a maior província carbonífera ainda não explorada no mundo.
O Projeto Moatize, foi iniciado em 2008 e envolveu não só a construção da mina, mas também de uma grande estrutura logística, até então inexistente no país.

A Vale venceu a licitação internacional para os direitos de mineração e exploração de carvão em Moçambique em 2004, contudo a operação somente foi iniciada em maio de 2011, com o primeiro carregamento de carvão enviado para o porto da Beira em agosto do mesmo ano. Em maio de 2012, um milhão de toneladas de carvão foram transportadas ao longo da linha ferroviária de cerca de $600 \mathrm{~km}$, por uma frota de 32 comboios e 638 vagões de minério (Marshall, 2012).

No mesmo ano, a mineradora tornou-se a maior investidora no país, com a primeira onda de investimentos somando US\$ 1,8 bilhão e a segunda devendo chegar a US\$ 6,4 bilhões. Além de uma nova mina que está sendo construída pela Odebrecht, a Vale está construindo uma ferrovia de 912 quilômetros, ligando a mina de Moatize ao porto de Nacala, onde também está levantando um porto (Estadão, 2013). Nesses projetos, há também a participação das construtoras Camargo Corrêa e OAS.

Desse modo, além da mina de carvão de Moatize operada pela Vale, as obras de infraestrutura que cercam esse projeto também são efetuadas por empresas brasileiras. Valendo destacar que todos possuem financiamentos do BNDES (Garcia, 2012), com o da mina podendo chegar a US\$ 125 milhões (Agência Brasil, 2004).

\section{BNDES}

O BNDES provê direta ou indiretamente financiamentos a médio e a longo prazo e que respondem, tradicionalmente, por algo em torno de $20 \%$ de todo o crédito do sistema bancário brasileiro ao setor privado (Deos, 2009). Atualmente, o BNDES desembolsa R \$ 52,9 bilhões para o setor de infraestrutura, R \$ 47,7 bilhões com a indústria, R\$ 44 bilhões com comércio e serviços e R $\$ 11,4$ bilhões com agropecuária (BNDES, 2013).

O programa de exportação passou por diversas modificações ao longo dos anos e, atualmente, essa linha chama-se Exim e conta com cinco modalidades de financiamento: pré-embarque, pré-embarque ágil, pré-embarque âncora; pré-embarque especial e pósembarque. Essas linhas, no entanto, não acontecem em muitas parcelas do total das exportações brasileiras, visto que são voltadas para os nichos de maiores externalidades, tais como manufaturas de alto valor agregado, softwares e serviços de engenharia. Além disso, a venda desses tipos de produtos necessita da concessão de um prazo de pagamento ao importador, e é aí que se insere a necessidade do apoio público, dado o risco comercial e o risco político (BNDES, 2013). Cabe destacar, também, que o banco somente financia o que é exportação, ou seja, não cobre os gastos locais.

Segundo Garcia (2012), na África, o BNDES procura acompanhar as negociações brasileiras nos 
fóruns internacionais, adequando sua política às regras acordadas pelo Brasil e contribuindo com os setores governamentais responsáveis pelas negociações. Dessa forma, a política do banco de apoio ao comércio exterior articula-se com as prioridades definidas pelo governo federal, com o intuito de desenvolver um tratamento diferenciado às operações com os países dessa região.

Nesse cenário, na África, os financiamentos chegaram, em 2009, a US\$ 766 milhões, o que representava cerca de $36 \%$ dos créditos internacionais disponíveis do BNDES (Leo, 2011). O MRE (2011) afirma que foram apoiadas algumas obras no continente, como o projeto de reconstrução do governo angolano realizado pelas quatro maiores construtoras brasileiras no valor de US\$ 3,5 bilhões; o projeto do aeroporto de Nacala, em Moçambique, no valor de US\$ 80 milhões; para o corredor rodoviário em Gana (Odebrecht e Andrade Gutierrez) orçado em US\$ 200 milhões; e o estudo de viabilidade da barragem de Moamba Major em Moçambique no valor de US\$ 8,5 milhões.

\section{As construtoras brasileiras em Moçambique: Camargo Corrêa, OAS e Odebrecht}

Como foi visto na seção anterior, o BNDES somente financia o que é exportação brasileira. Nesse sentido, com a licitação ganha por parte da Vale para explorar a mina de Moatize em Moçambique, haveriam de ser feitas obras estruturais na região para que a operação fosse suportada. Assim, empresas brasileiras de construção pesada foram contratadas para que essa infraestrutura fosse construída, sendo exemplo o porto de Nacala, a ferrovia que liga esse porto a mina, o aeroporto de Nacala e, até mesmo, as obras na mina.

Desse modo, cabe aqui registrar a presença das construtoras brasileiras em Moçambique. Segundo consta no relatório anual referente ao ano de 2007, a Camargo Corrêa teve como seu primeiro projeto nesse país: "Em Moçambique, no sudeste da África, a empresa participa do projeto de instalação da mina de carvão de Moatize, da Vale, que será uma das maiores do mundo" (Camargo Corrêa, 2008, p. 35). Com isso, nesse mesmo ano, a Camargo conseguiu outro projeto nesse país, referente a hidrelétrica de Mphanda Nkuwa, em Moçambique, cuja previsão dos investimentos era a de atingir US\$ 8 bilhões, valor superior ao PIB desse país (Camargo Corrêa, 2010). Consta, ainda, em seu relatório referente ao ano de 2012, que a Vale é um dos grandes investidores individuais na companhia que, juntamente com a Petrobrás, foi responsável pela criação de novos negócios que injetaram R $\$ 17$ bilhões na carteira de contratos (Camargo Corrêa, 2013).

A construtora OAS, por sua vez, é a responsável pela construção da estrutura na cidade de Nacala, incluindo aí o seu porto e obras do corredor MoatizeNacala. Nesse sentido, a Gerente de Apoio Internacional da construtora, em entrevista aos autores, afirmou que, a despeito da falta de incentivos do governo para a internacionalização da empresa, há essa possibilidade através das obras realizadas para a Vale, fazendo com que a OAS intensificasse sua presença no continente africano.

Por fim, a Odebrecht que, até 2008, somente possuía operações em Angola no que tange ao continente africano, conseguiu, nesse ano, seu primeiro projeto em Moçambique justamente para a Vale, que consistiu na construção da usina de beneficiamento para a mina de Moatize (Odebrecht, 2009). Essa entrada no mercado possibilitou a empresa novos contratos nesse país, iniciando, em 2013, as obras do BRT e da Zona Franca Industrial na cidade de Nacala (Odebrecht, 2014).

Desse modo, a licitação ganha pela Vale em Moçambique, com parte do financiamento do BNDES - que cedeu créditos para a parte de logística, de perfuração e de maquinários necessários para a abertura da mina (Folha de São Paulo, 2004) - pôde, além de outros fornecedores, internacionalizar três grandes construtoras brasileiras (Camargo Corrêa, OAS e Odebrecht) para esse país. 
Figura 3 -Vale e o transbordamento de suas operações no exterior

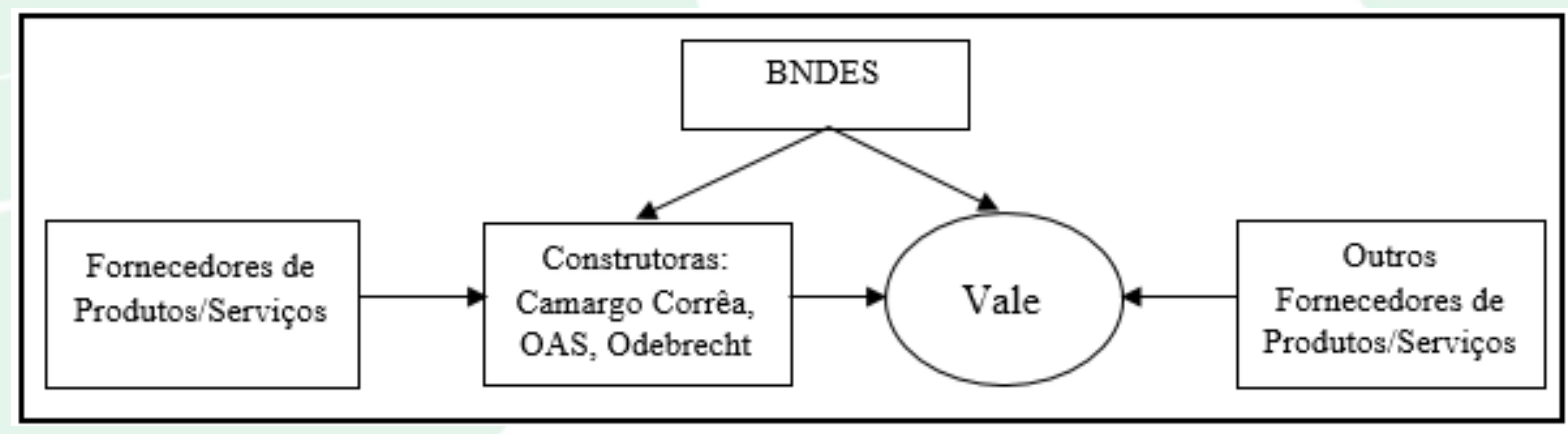

Fonte: elaborado pelos autores

Por sua vez, para operar, essas empreiteiras também obtiveram financiamento no banco estatal, trazendo consigo outros fornecedores para as obras. Desse modo, a obrigatoriedade de exportar produtos/serviços brasileiros para a consecução de empréstimos do BNDES possibilitou a internacionalização de outras empresas brasileiras.

Figura 4 - Fornecedores vinculados às exportações de serviços de engenharia: 2007 a 2014

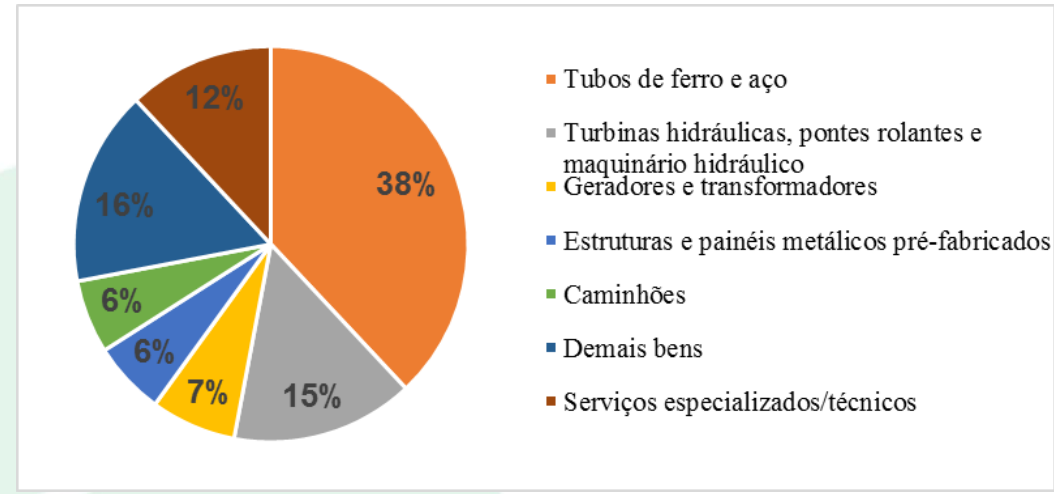

Fonte: Machado (2015)

Percebe-se, nesse caso, a Vale no centro da network responsável pela internacionalização de empresas para Moçambique. Dessa maneira, o risco percebido pelas construtoras e pelos outros fornecedores é reduzido em função de estarem prestando serviço para a Vale. Também é importante destacar que essas empresas não escolheram o local para o qual se internacionalizaram, sendo uma consequência do movimento internacional da Vale. Desse modo, praticamente não houveram barreiras ao movimento para o exterior das empreiteiras. Nesse sentido, a primeira internacionalização dessas construtoras para Moçambique por meio da Vale acelerou o processo de aprendizagem delas em relação à realidade desse país, possibilitando a elas a realização de novos projetos.

\section{DISCUSSÃO DOS CASOS}

Apesar de o foco do trabalho ser a ida da Vale e das construtoras para Moçambique, cabe destacar que o relacionamento entre essas empresas e o BNDES já ocorria em âmbito interno. $\mathrm{O}$ banco financiando as diversas obras de infraestrutura e de mineração no Brasil, enquanto que a relação da mineradora com as empreiteiras advém de obras de logística e de estrutura para as minas da Vale no país. Assim, a rede que possibilitou a ida da Camargo Corrêa, OAS e Odebrecht para Moçambique foi criada internamente e expandida para o exterior com a ida da CVRD para esse país, conforme ponto defendido por Johanson \& Vahlne (2009), no qual as redes são pré-existentes ao movimento internacional.

No que tange à internacionalização da Vale para Moçambique, essa ocorreu somente em virtude do financiamento do BNDES que possibilitou à empresa ganhar a licitação para operar a mina de Moatize. Desse modo, foi o acesso ao financiamento oferecido por um membro de sua rede (Coviello, 2006) que proporcionou o movimento internacional da CVRD, além das competências da empresa (que não estão no escopo deste trabalho). Já a internacionalização das construtoras foi um resultado desse movimento da Vale, visto que a obrigação da empresa em virtude do apoio do BNDES é a de utilizar exportações brasileiras, 
assim utiliza-se dos serviços das empreiteiras brasileiras que, por sua vez, também utilizam esse financiamento público para o seu movimento internacional. Dessa forma, o BNDES faz com que se internacionalizem membros da rede tanto da Vale quanto das construtoras.

Figura 5 - Rede Vale-BNDES-Construtoras no caso de Moatize

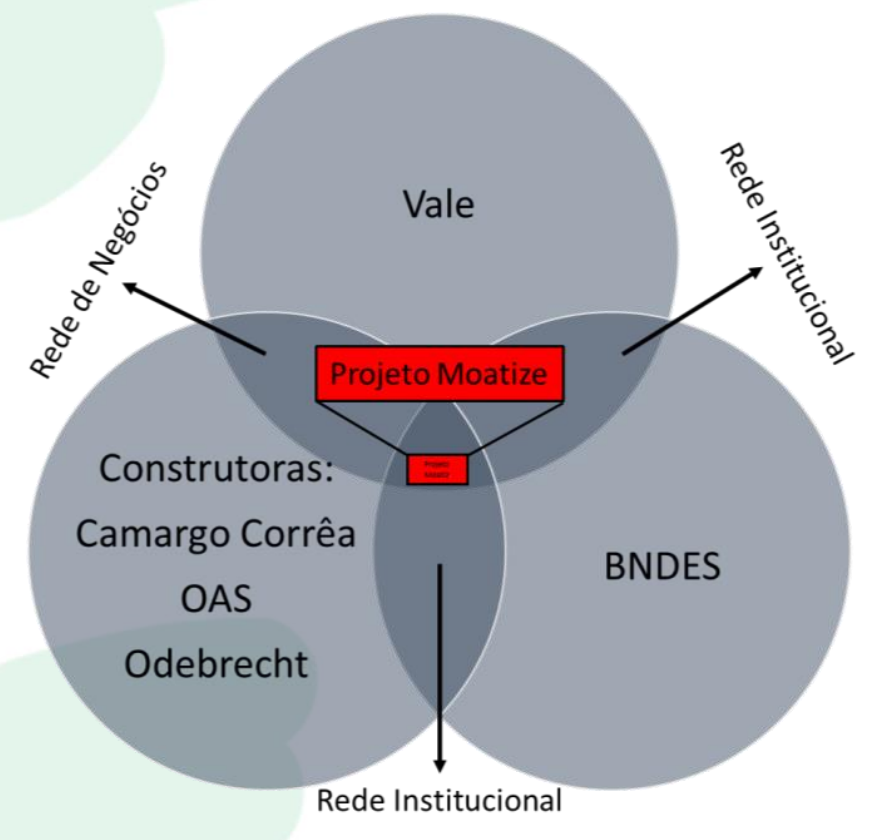

Fonte: elaborado pelos autores com base em Oparaocha (2015)

A internacionalização da Vale, dessa forma, teve de acionar a "rede institucional BNDES" e acionou a "rede de negócios construtoras" que, por sua vez, mobilizou a "rede institucional BNDES". Sendo assim, notou-se, no caso, que a internacionalização foi um resultado das iniciativas de um interessado em desenvolver um relacionamento pré-existente (Johanson \& Vahlne, 2009), com as construtoras sendo ser demandadas a seguir um parceiro, ou seja, a Camargo Corrêa, a OAS e a Odebrecht internacionalizaram-se para Moçambique a partir de um contato da Vale, já membro de suas redes. Desse modo, o processo iniciou-se quando um membro da rede (Vale) ativou os demais (construtoras e BNDES) em busca de recursos financeiros e de serviços (Ford \& Mouzas, 2013).

Em termos institucionais, conforme Welch \& Welch (1996) afirmam, os fatores contextuais e situacionais, como políticas governamentais e de apoio financeiro, tiveram um grande impacto nesse movimento. A atuação do BNDES como financiador reduziu o risco dos atuantes em um país arriscado para investimentos, além disso os créditos proporcionados pelo banco facilitam a internacionalização, visto que se tornam um diferencial na hora de fazer a proposta na licitação em Moçambique. Vale destacar que o risco de atuação foi reduzido, também, em função de uma atuação do governo brasileiro mais próxima do continente africano, por meio de embaixadas e de missões comerciais, mostrando que a atuação governamental é de grande importância para a internacionalização de empresas (Frischtak, 2003; Peng \& Parente, 2012) no caso brasileiro, conforme destacado pelo Gerente Internacional da Camargo Corrêa em entrevista aos autores:

O surgimento de África para gente ocorreu em um momento em que o governo brasileiro iniciou, de uma maneira mais extensiva, o apoio ao continente. Nesse contexto, na medida em que as relações do Brasil com Angola e com Moçambique começaram a se solidificar, a gente começou a enxergar uma oportunidade, já que teríamos um respaldo diplomático. Assim, não estaríamos indo para um mercado relativamente complexo totalmente sozinho, então na medida em que o governo começa a disponibilizar ferramentas mais consistentes de financiamento para obra, que o governo estrutura sua embaixada, a gente se sente um pouco mais respaldado para ir para um mercado complexo como é o africano.

Assim como proposto pela perspectiva de Redes, portanto, a escolha do país e do processo de internacionalização ocorreu devido à influência das redes internacionais estabelecidas pelas construtoras com a Vale, o que permitiu a redução do risco percebido, tendo assim um resultado similar ao da redução da distância psíquica (Carneiro \& Dib, 2007), 
reduzindo as incertezas enfrentadas pelas empresas (Peng, 2006; Scott, 2008). Dessa maneira, a atuação das instituições brasileiras, aliada à presença de redes de relacionamento, tanto de negócios quanto institucionais, reduziram os riscos para uma primeira entrada das construtoras em Moçambique, o que foi tido como aprendizado (Johanson \& Vahlne, 2009) para, em seguida, obterem outros projetos nesse país.

\section{CONCLUSÃO}

O presente artigo mostrou como as construtoras brasileiras Camargo Corrêa, OAS e Odebrecht se internacionalizaram para Moçambique, tendo por base, principalmente, a perspectiva de redes e a Teoria Institucional. A primeira ajudou a perceber como o movimento de membros da rede, no caso a Vale, possibilitou a ida dessas empresas para o exterior, enquanto que a segunda demonstrou que, principalmente em países emergentes, o apoio governamental é preponderante para a internacionalização de empresas.

Esse último caso fica ainda mais claro quando se percebe que a internacionalização tardia das empresas brasileiras ocorrida, principalmente, a partir dos anos 1990, tem como grande ator o BNDES, que passou a instrumento da política de apoio ao comércio exterior nessa década, sendo importante a contrapartida de somente financiar o que é exportação nacional, o que amplia o efeito dos empréstimos, transbordando para a cadeia de suprimentos das empresas.

Já em relação ao caso Vale, esse possibilitou a ida para Moçambique de três grandes empreiteiras brasileiras - Camargo Corrêa, OAS e Odebrecht - que foram contratadas para a construção de obras de logística e de estrutura da mina de Moatize. Assim, nota-se a importância e a atuação internacional de membros de uma rede para a internacionalização de outras empresas que vão para o exterior mediante o efeito bandwagon proporcionado. Desse modo, percebe-se que o ganho da licitação em Moçambique pela Vale criou oportunidades internacionais para as construtoras, bem como para seus provedores de serviços/produtos. Ademais, proporcionou às construtoras de sua rede de contatos um ambiente menos arriscado, em virtude de seu contrato ser com a Vale e do impacto proporcionado por políticas governamentais de apoio e de crédito.

Sendo assim, sob o ponto de vista teórico, o artigo oferece um abordagem que leva em conta a integração entre a perspectiva de redes e de instituições, o que pode oferecer uma perspectiva complementar capaz de enriquecer a análise de situações análogas, visto que pelo fato de o BNDES exigir uma contrapartida em exportação para o pedido de financiamento, o tipo movimento de rede aqui apresentado deve ser comum. Além disso, coloca no centro das discussões do papel do BNDES para a internacionalização de empresas brasileiras como provedor de financiamento.

Em termos gerenciais, ressalta a importância dos relacionamentos de negócios e institucionais para o movimento internacional das empresas, bem como do papel preponderante do governo brasileiro para isso, cabendo, inclusive, uma reflexão acerca dos benefícios e das limitações dessa atuação.

\section{REFERÊNCIAS}

Agência Brasil (2004). BNDES aguarda proposta técnica para financiar projeto da Vale em Moçambique. Agência Brasil, 16 de Novembro de $2004 . \quad$ Disponivel em: http://memoria.ebc.com.br/agenciabrasil/noticia/20 04-11-16/bndes-aguarda-proposta-tecnica-parafinanciar-projeto-da-vale-em-mocambique. Acessado em novembro de 2015.

Alem, A. \& Cavalcanti, C. E. (2005). O BNDES e o apoio à internacionalização das empresas brasileiras: algumas reflexões. Revista do BNDES, dezembro, 12: 24: 43-76.

Anderson, J., Hákanson, H. \& Johanson, J. (1994). Dyadic Business Relationships within a Business Network Context. Journal of Marketing, 58: 4: 115.

Arrow, K. (1998). The place of institutions in the economy: a theoretical perspective. In: Hayami, Y. \& Aoki, M. (orgs). The institutional foundation of East Asian economic development: proceedings of the IEA conference held in Tokyo, Japan, International Economic Association Series, pp. 3948, Londres: Macmillan UK.

Audet, J. \& St-Jean, E. (2007). Factors affecting the use of public support services by SME owners: evidence from a periphery region of Canada. Journal of Developmental Entrepreneurship Theory and Practice, 35: 1: 11-37.

Banco Nacional de Desenvolvimento Econômico e Social (BNDES). (2013). BNDES: Relatório Anual 2012. Banco Nacional de Desenvolvimento Econômico e Social, Rio de Janeiro, Brasil.

Barnir, A. \& Smith, K. (2002). Interfirm alliances in the small business: the role of social networks. Journal of Small Business Management, 40: 3: 219232.

Beckerman, W. (1956). Distance and the pattern of intra-european trade. The Review of Economics and Statistics, 38: 1: 31-40. 
Bell, S. (2002). Institutionalism: old and new. In: Summers, J. (ed.) Government, Politics, Power and Policy in Australia. 7th ed. pp. 363-380. Ed. NSW Australia: Pearson Education Australia.

Björkman, I. \& Forsgren, M. (2000). Nordic international business research: a review of its development. International Studies of Management and Organization, 30: 1: 6-25.

Camargo Corrêa. (2008). Relatório anual 2007. Camargo Corrêa, São Paulo, Brasil.

Camargo Corrêa. (2010). Relatório anual 2009. Camargo Corrêa, São Paulo, Brasil.

Camargo Corrêa. (2013). Relatório anual 2012. Camargo Corrêa, São Paulo, Brasil.

Carlson, S. International Business Research. (1966). Uppsala: Acta Universitatis Upsaliensis.

Carneiro, J. \& Dib, L. A. (2007). Avaliação comparativa do escopo descritivo e explanatório dos principais modelos de internacionalização de empresas. INTERNEXT - Revista Eletrônica de Negócios Internacionais da ESPM, São Paulo, 2: 1: $1-25$, jan./jun.

Coviello, N. (2006). The network dynamics of international new ventures. Journal of International Business Studies, 37: 5: 713-731.

Coviello, N. \& Munro, H. (1995). Growing the entrepreneurial firm: networking for international marketing development. European Journal of Marketing, 29: 7: 49-61.

Coviello, N. \& Munro, H. (1997). Network relationships and the internationalization process of small software firms. International Business Review, 6: 4: 361-386.

Czinkota, M. \& Ursic, M. (1991). Classification of Exporting Firms According to Sales and Growth into a Share Matrix. Journal of Business Research, 22: 3: 243-253.

Deos, S. (2009). Perspectivas do investimento na dimensão Mercosul e integração da América Latina. Projeto Perspectivas do Investimento no Brasil. Rio de Janeiro: UFRJ.

Dunning, J. \& Mucchielli, J. (2001). Multinational Firms: The global-local dilemma. London and New York: Routledge.

Estadão. (2013). Vale se torna a maior investidora do Brasil na África e é alvo de críticas. Estadão, 31 de outubro de 2013. Disponível em: http://brasil.estadao.com.br/noticias/geral,vale-setorna-a-maior-investidora-do-brasil-na-africa-e-ealvo-de-criticas, 1091746. Acessado em novembro de 2015 .

Exame. (2013). As 50 maiores exportadoras em 2012 do Brasil. Revista Exame, 23 de janeiro. Disponível em: http://exame.abril.com.br/negocios/noticias/as50-maiores-exportadoras-em-2012-do-brasil?p=2. Acessado em novembro de 2015.

Ferreira, I. (2011). A influência da distância cultural na escolha do IDE adequado no processo de internacionalização das empresas: uma visão teórica. Revista Ibero-Americana de Estratégia RIAE, São Paulo, 10: 1: 147-169, jan/abr.

Flynn, M. (2007). Between subimperialism and globalization: a case study in the internationalization of brazilian capital. Latin American Perspectives, 157: 34: 6: 9-27, November.

Folha de São Paulo. (2004). BNDES destina US\$ 125 mi a projeto da Vale. Jornal Folha de São Paulo, 17 de novembro de 2004. Disponível em: http://www1.folha.uol.com.br/fsp/dinheiro/fi17112 00424.htm. Acessado em novembro de 2015.

Ford, D. \& Mouzas, S. (2013). The theory and practice of business networking. Industrial Marketing Management, 42: 433-442.

Forsgren, M. (2002). The concept of learning in the Uppsala internationalization process model: a critical review. International Business Review, 11: 257-277.

Frischtak, C. (2003). Latin America. In: Dunning, J. (Org.). Governments, Globalization and International Business. pp. 431-454, New York: Oxford University Press.

Fundação Dom Cabral. (2014). Ranking das multinacionais brasileiras 2013. Fundação Dom Cabral. Disponível em: http://www.fdc.org.br/imprensa/Documents/2013/ra nking_multinacionais__ brasileiras2013.pdf. Acessado em novembro de 2015.

Garcia, A. (2012). A internacionalização de empresas brasileiras durante o governo Lula: uma análise crítica da relação entre capital e Estado no Brasil contemporâneo. Tese de Doutorado em Relações Internacionais não publicada. Pontifícia Universidade Católica do Rio de Janeiro.

Garcia, S., Lima, G. \& Carvalho, D. (2010). Redes interorganizacionais de cooperação para a 
internacionalização. Revista de Gestão (REGE), 17: 2: 209-224.

Ghauri, P., Lutz, C. \& Tesfom, G. (2003). Using networks to solve export-marketing problems of small - and medium - sized firms from developing countries. European Journal of Marketing, 37: 5/6: 728-752.

Globerman, S. \& Shapiro, D. (1999). The impact of government policy on foreign direct investment: the Canadian experience. Journal of International Business Studies, 30: 513-532.

Granovetter, M. (1985). Economic Action and Social Structure: The Problem of Embeddedness. American Journal of Sociology, 91: 481-510.

Hákanson, L. \& Ambos, B. (2010) The antecedents of psychic distance. Journal of International Management, 16: 195-210.

Hanson II, J. (1999). Culture shock and direct investment in poor countries. Journal of Economic History, 59: 1-16.

Hemais, C. A. \& Hilal, A. (2001). Da aquisição de conhecimento à network: a visão evolucionária da Escola Nórdica de Negócios Internacionais. Série Relatórios COPPEAD, Rio de Janeiro: UFRJ/COPPEAD.

Huggings, R., Johnston, A. \& Thompson, P. (2012). Network capital, social capital and knowledge flow: how the nature of inter-organizational networks impacts on innovation. Industry and Innovations, 19: 3: 203-232.

Johanson, J. \& Mattson, L.G. (1993). Internationalization in industrial systems: a network approach. In: Buckley, P. \& Ghauri, P. The internationalization of the firm: a reader, pp. 303321, London: Academic Press.

Johanson, J. \& Vahlne, J. (1977). The internationalization process of the firm - a model of knowledge development and increasing foreign market commitments. Journal of International Business Studies, 8: 1: 23-32.

Johanson, J. \& Vahlne, J. (2009). The Uppsala internationalization process model revisited: from liability of foreignness to liability of outsidership. Journal of International Business Studies, 40: 1411-1431.

Johanson, J. \& Wiedersheim-Paul, F. (1975). The internationalization of the firm - four cases. Journal of Management Studies, 12: 305-322.
Lee, S., Peng, M. \& Barney, J. (2007). Bankruptcy law and entrepreneurship development: a real options perspective. Academy of Management Review, 32: 1: $257-272$.

Leo, S. (2011). País elabora estratégia para se tornar mais competitivo na África. Valor Econômico, 8 de novembro. Disponível em: http://www.valor.com.br/brasil/1086310/paiselabora-estrategia-para-se-tornar-mais-competitivona-africa Acessado em: outubro de 2015.

Machado, L. (2015). Financiamentos à exportação: 2003-2015. Banco Nacional do Desenvolvimento Econômico e Social. Apresentação em Audiência Pública na Câmara dos Deputados. Disponível em: http://www2.camara.leg.br/atividade-

legislativa/comissoes/comissoestemporarias/parlamentar-de-inquerito/55alegislatura/cpi-bndes/documentos/audienciaspublicas/ApresentaoLuciene_010915_FINALLucie ne.pdf Acessado em novembro de 2015.

Marshall, J. (2012). Mega-projectos de mineração $e$ trabalho: trabalhar para a Vale " a pior empresa do mundo": casos do Canadá, Brasil e Moçambique. Artigo apresentado na III Conferência Internacional Do IESE "Moçambique: Acumulação e Transformação em Contexto de Crise Internacional", Conference Paper n. 21, Maputo, Moçambique, 4 e 5 de setembro de 2012.

Martinez, R. \& Dacin, M. (1999). Efficiency Motives and Normative Forces: Combining Transaction Costs and Institutional Logic. Journal of Management, 25: 1: 75-96.

Mcdougall, P. \& Oviatt, B. (2005). Defining international entrepreneurship and modeling the speed of internationalization. Entrepreneurship Theory \& Practice, 29: 5: 537-553.

Meyer, K. (2001). Institutions, transaction costs, and entry mode choice in Eastern Europe. Journal of International Business Studies, 32: 2: 357-367.

Meyer, K. \& Peng, M. (2016). Theoretical foundations of emerging economy research. Journal of International Business Studies, 47: 1: 3-22.

Meyer, J. \& Rowan, B. (1977). Institutionalized organizations: formal structure as myth and ceremony. American Journal of Sociology, 83: 2: 340-363.

Ministério das Relações Exteriores (MRE). (2011). Balanço da Política Externa 2003-2010. Disponível em http://www.itamaraty.gov.br Acessado em dezembro de 2014. 
Mudambi, R. \& Navarra, P. (2002). Institutions and international business: a theoretical overview. International Business Review, 11: 6: 635-646.

North, D. (1990). Institutions, institutional change and economic performance. New York: Cambridge University Press.

Odebrecht. (2009). Relatório anual 2008. Odebrecht, Rio de Janeiro, Brasil.

Odebrecht. (2014). Relatório anual 2013. Odebrecht, Rio de Janeiro, Brasil.

O Globo (2015). Com economia fraca, mais empresas brasileiras abriram filiais no exterior. Jornal $O$ Globo, 09 de setembro de 2015. Disponível em: http://oglobo.globo.com/economia/com-economiafraca-mais-empresas-brasileiras-abriram-filiais-noexterior-17438866. Acessado em novembro de 2015.

Oparaocha, G. (2015). SMEs and international entrepreneurship: an institutional network perspective. International Business Review, 24: 861-873.

Peng, M. (2006). Global Strategy. Cincinnati, Ohio: South-Western Thomson.

Peng, M. \& Heath, P. (1996). The growth of the firm in planned economies in transition: institutions, organizations, and strategic choices. Academy of Management Review, 21: 492-528.

Peng, M. \& Parente, R. (2012). Institution-based weaknesses behind emerging multinationals. Revista de Administração de Empresas, 52: 3: 360364.

Penrose, E. (1995). The theory of the growth of the firm. Oxford: Basil Blockwell.

Rocha, A., Silva, J. \& Carneiro, J. (2007). Expansão internacional das empresas brasileiras: revisão e síntese. In: Fleury, A. \& Fleury, M.T. (Orgs.). Internacionalização e os países emergentes, pp.183-197, São Paulo: Atlas.

Scott, W. (2008). Institutions and organizations: ideas and interests. 3rd. ed. Los Angeles, CA: Sage.
Sharma, D. \& Blomstermo, A. (2003). The internationalization process of Born Globals: a network view. International Business Review, 12: 739-753.

Silva, M., Rocha, A. \& Figueiredo, O. (2007). Medindo o construto da distância psíquica. $E \& G$ : Economia e Gestão, 7: 14: 85-106.

Slotte-Kock, S. \& Coviello, N. (2009). Entrepreneurship research on network processes: a review and ways forward. Entrepreneurship Theory and Practice, 34: 1: 31-57.

Tong, T., Reuer, J. \& Peng, M. (2008). International Joint Ventures and the Value of Growth Options. The Academy of Management Journal, 51: 5: 10141029.

Vahlne, J., Ivarsson, I. \& Johanson, J. (2011). The tortuous road to globalization for Volvo's heavy truck business: extending the scope of the Uppsala Model. International Business Review 20: 1-14.

Vahlne, J. \& Johanson, J. (2013). The Uppsala model on evolution of the multinational business enterprise - from internalization to coordination of networks. International Marketing Review, 30: 3: 189-210.

Vale. (2012). Vale: nossa história. Rio de Janeiro: Verso Brasil.

Welch, D. \& Welch, L. (1996). The internationalization process and networks: a strategic management perspective. Journal of International Marketing, 4: 3: 11-28.

Yin, R. (1994). Case study research: Design and methods. $2^{\mathrm{a}}$ Ed. Newbury Park, CA: Sage Publishing.

Zain, M. \& Ng, S. (2006). The impacts of network relationships on SME's internationalization process. Thunderbird International Business Review, 48: 2: 183-205.

Zanni, P., De Moraes, G. \& Marrioto, F. (2011). Para que servem os estudos de caso único?. Artigo apresentado no XXXV Encontro da associação nacional de pós-graduação em administração (ENANPAD) 2011, Rio de Janeiro, Brasil. 